\title{
The effect of Gl endoscopy nurse experience on screening colonoscopy outcomes
}

\author{
Evan S. Dellon, MD MPH ${ }^{1,2}$, Quinn Kerr Lippmann, BA ${ }^{1}$, Joseph A. Galanko, $\mathrm{PhD}^{1}$, Robert \\ S. Sandler, MD MPH ${ }^{1}$, and Nicholas J. Shaheen, MD MPH ${ }^{1,2}$ \\ ${ }^{1}$ Center for Gastrointestinal Biology and Disease, Division of Gastroenterology and Hepatology, \\ University of North Carolina School of Medicine, Chapel Hill, NC \\ ${ }^{2}$ Center for Esophageal Diseases and Swallowing, Department of Medicine, University of North \\ Carolina School of Medicine, Chapel Hill, NC
}

\section{Abstract}

Background-The effect of gastrointestinal endoscopy nursing experience on colonoscopy outcomes is unknown.

Objective-To determine whether nurse experience was associated with screening colonoscopy complications, procedure length, and cecal intubation.

Design-Retrospective analysis of screening colonoscopies performed by attending physicians between August 2003 and August 2005. Nurse experience was measured in weeks.

Setting-University of North Carolina Hospitals.

Subjects-Twenty-nine nurses were employed during the study period, 19 of whom were newly hired. A total of 3,631 eligible screening colonoscopies were analyzed.

\section{Interventions-N/A}

Main outcome measurements-The primary outcome was any immediate complication; secondary outcomes included time to cecum, total procedure time, and cecal intubation rate.

\begin{abstract}
Results-In procedures staffed by nurses with 2 weeks of experience or less, $3.2 \%$ had complications compared with $0.3 \%$ for procedures with more experienced nurses (OR 10.4, 95\% CI $3.55,30.2)$. For nurses with 6 months of experience or less, $18 \%$ of procedures had cecal intubation times greater than one standard deviation above the mean compared with $12 \%$ for more experienced nurses (OR 1.60, 95\% CI 1.30, 1.97). Similar results were seen for total procedure duration (OR 1.61,
\end{abstract}

(C) 2009 American Society for Gastrointestinal Endoscopy. Published by Mosby, Inc. All rights reserved.

Corresponding Author: Evan S. Dellon MD MPH CB\#7080 Bioinformatics Building 130 Mason Farm Rd. UNC-CH Chapel Hill, NC 27599-7080 United States Phone: (919) 966-2513 Fax: (919) 843-2508 edellon@med.unc.edu.

Author contributions:

- Evan Dellon: conception; design; analysis; interpretation; drafting manuscript; critical revision; final approval.

- Quinn Lippmann: analysis; critical revision; final approval.

- Joseph Galanko: analysis; critical revision; final approval.

- Robert Sandler: interpretation; critical revision; final approval.

- Nicholas Shaheen: conception; interpretation; critical revision; final approval.

This study was presented as two oral presentations at DDW, Washington D.C., May, 2007.

No conflicts of interest pertaining to this study exist for any of the authors.

Publisher's Disclaimer: This is a PDF file of an unedited manuscript that has been accepted for publication. As a service to our customers we are providing this early version of the manuscript. The manuscript will undergo copyediting, typesetting, and review of the resulting proof before it is published in its final citable form. Please note that during the production process errors may be discovered which could affect the content, and all legal disclaimers that apply to the journal pertain. 
95\% CI 1.32, 1.97) and cecal intubation rates (OR 1.81, 95\% CI 1.37, 2.39). All relationships held after adjusting for potential confounding factors.

Limitations-Retrospective, single center study.

Conclusions-Gastrointestinal endoscopy nurse inexperience is associated with an increase in immediate complications, prolonged procedure times, and decreased cecal intubation rates for screening colonoscopies. These findings have implications for nurse training, procedure efficiency, colonoscopy quality assessment, and patient safety.

\section{Keywords}

Colonoscopy; Nursing; Outcomes

Screening colonoscopy is felt to be a safe, efficacious, and cost-effective strategy for the prevention of colorectal cancer. As such, it is recommended by a number of national organizations for everyone at the age of 50 , and for selected populations at a younger age. ${ }^{1-3}$ Gastroenterologists, however, are cognizant of the measurable risks of colonoscopy. Potential complications include: pain; infection; bleeding requiring transfusion or hospitalization $(2.5 \%$ of cases post-polypectomy); perforation ( $0.4 \%$ of all cases and $1 \%$ of cases post-polypectomy); respiratory events such as aspiration or respiratory depression (1-5\% of cases); cardiovascular events such as arrhythmia or hypotension ( $1 \%$ of cases); and even death (0-0.03\% of cases). $4-7$

Because of these risks, a number of investigators have identified predictors of so-called "difficult" colonoscopies, procedures that are either associated with complications or increased procedure times. Physician inexperience is one such factor, which can be ameliorated with rigorous training. ${ }^{8-12}$ There are also a number of patient-related factors, including increased age, female sex, poor bowel preparation, lower body mass index (BMI), prior abdominal surgery and prior hysterectomy in particular, complicated diverticular disease, and a history of constipation or laxative use. ${ }^{7},{ }^{1-21}$ It is unknown, however, whether factors related to GI endoscopy nurse experience impact colonoscopy outcomes.

The Society for Gastroenterology Nurses and Associates (SGNA) has published on-line training guidelines which state that the GI endoscopy nurse "completes an orientation based on individual learning needs... and practice setting... and identifies learning needs based on performance behaviors...."22 Accordingly, our center individualizes training for each endoscopy nurse based on prior nursing experience, with graduated responsibility and independence as well as supervision by a more experienced nurse during at least the first two to four weeks of procedural experience. In recent years, however, our GI procedures unit has had a high rate of nurse turnover resulting in a cohort of nurses with relatively little initial GI endoscopy nursing experience. Our clinical impression was that this change had a potential impact on colonoscopy outcomes, but the overall effect was not known. The aim of this study, therefore, was to determine whether the experience level of GI endoscopy nurses was associated with screening colonoscopy outcomes including complications, procedure times such as time to cecum and total procedure time, and cecal intubation rate. We hypothesized that nurse inexperience is associated with increased screening colonoscopy complications, increased procedure times, and decreased cecal intubation rates.

\section{METHODS}

This was a retrospective study of outpatient screening colonoscopies performed from August 2003 through August 2005 at University of North Carolina (UNC) Hospitals' two GI procedure units, a hospital-based unit and an off-site outpatient-only unit. All procedures with a diagnostic 
indication were excluded. Procedures in which GI fellows were involved were excluded from this study to eliminate any potential trainee effect on outcomes. All data were captured from electronic endoscopy databases (ProvationMD and ProvationRN, Provation Medical, Minneapolis, MN) and from the electronic medical record of the UNC Hospitals. These databases are maintained for clinical purposes, and all data are entered by physicians and nurses in the course of routine clinical care.

The main exposure, nursing experience, was measured in weeks from the initial calendar time of the start date in a GI procedures unit to the calendar time of the specific procedure date. This time excluded any general orientation time in a procedures unit and marked the first procedure in which each nurse was involved. For nurses starting employment during the study time frame, exact start dates were known; none of the new nurses had prior experience in a GI procedures unit and all training and initial experience was obtained at the UNC inpatient unit. For nurses already working in our procedure units at the start of the study time frame, previous start dates in any endoscopy unit were determined from employment records. Therefore, a level of nurse experience was known for every nurse participating in every colonoscopy during the study period, and during the course of the study, a given nurse might have participated in some cases as an inexperienced nurse and in some cases as an experienced nurse. When two nurses were present during a procedure (with the more experienced nurse training and mentoring the less experienced nurse), the experience level of the less experienced nurse was assigned to the case. At our center, nurses administer sedation under physician orders as individualized to each patient, monitor patients, and assist with technical aspects of the procedure, but do not perform any part of the endoscopy. Nurses staffing a given procedure were identified from the finalized report in our electronic endoscopy database. Because nursing experience was not normally distributed, and because a nurse's experience continually changed throughout the study time period, nurse experience was categorized for analysis based on the data distribution. Since this had not been previously studied, categories could not be determined a priori. We attempted, however, to determine a threshold level of experience for each of our outcomes that might translate to a clinically useful end-point; where needed, sensitivity analyses were performed.

The primary outcome for this study was the occurrence of any immediate procedural complication, as recorded in the endoscopy database. Complications were defined as: respiratory depression unresponsive to supplemental oxygen, with or without use of reversal agents; hypotension requiring pharmacologic support or fluid bolus; cardiac arrhythmia (bradycardia with heart rate $<60$, heart block, non-sinus tachyarrhythmia with heart rate $>100$ ), with or without use of reversal agents; colonic perforation; and death. Of note, our endoscopy unit uses continuous ECG cardiac monitoring. Because this was a retrospective study and because our unit's catchment area is too broad, the occurrence of delayed complications could not be assessed.

Secondary outcomes included time to cecum, total procedure time, and cecal intubation rate, as recorded in minutes in the endoscopy database. Because the procedure times were not normally distributed and because small differences in procedure durations are not clinically significant, they were dichotomized at one standard deviation above the mean for analysis. Cecal intubation rate was defined as the proportion of cases in which the colonoscope was advanced to the cecum, as documented by the endoscopist, given that the bowel preparation was adequate and that an attempt to reach the cecum was made (ie that the recto-sigmoid junction was passed). This eliminated cases which were terminated early for severe colonic inflammation or technical reasons, as well as those that did not adequately view all of the colonic mucosa due to inadequate prep.

Other covariates of interest included procedural factors such as: physician-assessed bowel preparation quality; doses of medications administered; depth of colonoscope insertion; 
physician-assessed difficulty of the procedure and patient tolerance; findings (diverticulosis; polyps) and maneuvers (polypectomy); and the number of nurses present during each procedure. Patient factors of interest were also assessed and these included: patient age; sex; American Society of Anesthesiologists (ASA) classification ( $1=$ normal healthy patient; 2 = mild to moderate, well-controlled systemic disease; $3=$ severe systemic disease; $4=$ incapacitating disease that is a constant risk to life; $5=$ moribund patient not expected to survive 24 hours without an operation); ${ }^{23}$ body mass index (BMI; calculated as body weight in kilograms divided by height in square meters); comorbidities including coronary artery disease (CAD) or hypertension (HTN), diabetes (DM), obstructive sleep apnea (OSA) or snoring, and chronic obstructive pulmonary disease (COPD) or other respiratory disease; and past surgical history including hysterectomy, bowel resection, hernia surgery, cholecystectomy,

appendectomy, or other abdominal surgery. Each of these covariates is routinely recorded in our endoscopy databases during patient intake process prior to the procedure.

Statistical analysis was performed with Stata version 9 (StataCorp, College Station, TX). Routine descriptive summary statistics and bivariate analysis were conducted initially. Chisquare was used for comparisons between categorical variables, and Student's t-test was used for continuous variables. Multivariable analysis was conducted with logistic regression and an analysis of covariance strategy. Specifically, all potential confounders were included in an initial model for each outcome. Then, a backwards elimination approach was used to remove variables that did not change the odds ratio (OR) substantially, defined a priori as a total change in estimate of $10 \%$ or less. Additionally, to assess for the possibility of overfitting of the model due to limited numbers of outcomes for procedural complications, reduced models containing two covariates of interest and the outcome variable were assessed; adjusted OR's from these reduced models were compared to the OR's of the fully adjusted models. Because physician experience was non-differentially distributed between experienced and inexperienced nurses (in our units, both doctors and nurses rotate between procedure rooms without a set pattern), physician experience was not included in the initial regression model, but modelling was repeated with an added parameter for physician procedural volume during the study time frame to assess any effect on the estimated odds ratio. Because nurses participated in cases at both the hospital-based and the outpatient procedure units, location of the procedure was not included in the regression models. Similarly, because having two nurses present during a procedure was a proxy measure for the main exposure of interest, this covariate was not included in the models. Finally, for each outcome, all interactions between the exposure and potential confounding covariates were assessed at once with a likelihood ratio test. Because there were no significant interactions by this test, interaction terms were not included in the models. Missing data were excluded from bivariate and multivariable statistical analysis.

This study protocol was approved by the UNC School of Nursing Institutional Review Board.

\section{RESULTS}

\section{Patient characteristics}

A total of 3,614 patients, accounting for 3,631 screening colonoscopies, were identified from the electronic databases and were included in the study (Table 1). There were 17 patients who had repeat procedures due to inadequate bowel preparation. The mean patient age was 58.4 (range: 21-90), and $42 \%$ were male. The mean BMI was 27.7 (range: 14-76), with $64 \%$ of the study population categorized as either overweight $(\mathrm{BMI}>25)$ or obese $(\mathrm{BMI}>30)$. The presence of any comorbidity was identified in $86 \%$ of subjects, and $47 \%$ had more than one comorbidity. Physician-assessed ASA classification, however, indicated that the vast majority had only mild to moderate, well controlled, systemic disease (97\% with ASA score of 1 or 2). More than half of patients had at least one past abdominal surgery, with $24 \%$ having had hysterectomy and $22 \%$ having had appendectomy. 


\section{Nurse characteristics and nursing experience}

A total of 29 GI endoscopy nurses were employed over the study time frame (Table 2). Ten nurses were present at the beginning of the time frame and 15 were present at the end, corresponding to 19 new nurses hired over the study period and 14 nurses leaving over the same time span. The mean nurse experience for the primary nurse involved in the procedure was 157 weeks (range 1-583). The distribution of nursing experience was as follows: 157 procedures (4\%) were staffed by a nurse with $0-2$ weeks of experience; 912 by a nurse with 3 weeks to 6 months of experience (25\%); 418 by those with 7-12 months experience (11\%); 542 by those with $13-24$ months (15\%); 61 with $25-36$ months (2\%); 383 with $37-48$ months (11\%); 289 with 49-60 months (8\%); and 869 were staffed by a nurse with greater than 60 months of experience (24\%). There was no association between nurse experience and patient demographic characteristics or comorbidities (data not shown).

\section{Procedure characteristics}

The 3,631 screening colonoscopies included in this study comprised $37 \%$ of the total of 9,790 colonoscopies performed during the study time frame (Table 3 ). The remainder were cases in which GI fellows were involved and/or were colonoscopies performed for reasons other than screening. Overall, 20 different attending physicians (all experienced colonoscopists with greater than 1,000 procedures completed) performed a mean of 181 colonoscopies (range during the study time frame: 11-554). Procedures with fellow involvement, as noted above, were excluded. There was no association between physicians and specific nurses, as both doctors and nurses rotate between procedure rooms without a set pattern.

A mean of $124 \mathrm{mg}$ of fentanyl and $4 \mathrm{mg}$ of midazolam were used for conscious sedation. Physician-reported bowel preparation was excellent or good in $78 \%$ of procedures, and was not reported in $7 \%(\mathrm{n}=267)$. Physicians rated approximately $11 \%$ of cases as difficult, and did not report a difficulty level in $10 \%(\mathrm{n}=368)$. Overall, physicians reported a subjective impression that $87 \%$ of patients tolerated the procedure either "well" or "fairly well".

\section{Immediate complications}

The primary outcome of any immediate complication occurred 16 times $(0.4 \%)$ (Table 3$)$. Seven complications were due to bradycardia, 2 were due to hypotension, and 7 were due to respiratory depression. No immediate colonic perforations or deaths were recorded in our database, and no patients required hospital admission or intubation. Reversal agents, including atropine, naloxone, and flumazenil, were used in 11 patients. Details from each of the 16 cases with a complication are provided in Table 4 . For 15 of the patients, the age range was from 47 to 83 years; one 27 year-old undergoing screening for a high risk indication also experienced a complication. Thirteen different nurses participated as the primary nurse in these cases, and 5 of the cases were staffed by two nurses. Seven physicians were involved in the 16 cases, and there was no association between physician and complication $(\mathrm{p}=0.17)$ or nurse and complication $(\mathrm{p}=0.17)$ On bivariate analysis (Table 5), complications were associated with having multiple past abdominal surgeries ( $1.2 \%$ of patients with multiple past abdominal surgeries had a complication compared to $0.4 \%$ of patients without multiple past surgeries; $p$ $=0.03$ ) and with lower BMI (patients having complications had a mean BMI of 23.8 compared to patients without complications who had a mean BMI of 27.7; $p=0.01$ ).

The occurrence of a complication was associated with nurse inexperience. Thirteen of the 16 total complications $(81 \%)$ occurred during procedures staffed by nurses hired during the study period. While 8 complications occurred during procedures staffed by a nurse with 6 months of experience or less in a GI endoscopy unit (OR 2.4, 95\% CI 0.9-6.4), the highest proportion of complications (as a percentage of the total number of procedures) occurred during procedures staffed by a nurse with 2 weeks of experience or less (Figure 1). Specifically, complications 
occurred during $3.2 \%$ of these procedures ( 5 of 157 ) compared with $0.3 \%$ of procedures (11 of 3,474 ) staffed by nurses with greater than 2 weeks of experience ( $p<0.001$ by chi-square; $\mathrm{OR}_{\text {crude }}=10.4,95 \% \mathrm{CI} 3.55,30.2$ ). This association held after the multivariable analysis (Table 6) adjusting for potential confounding factors including patient age, sex, bowel preparation quality, BMI, ASA score, presence of multiple comorbidities, multiple past abdominal surgeries, past hysterectomy, severe diverticulosis, and polypectomy $\left(\mathrm{OR}_{\text {adjusted }}=10.5,95 \%\right.$ CI $2.26,49.1)$. The addition of physician procedure volume to the model also did not change this result.

\section{Cecal intubation time}

The mean cecal intubation time was 11.0 minutes (range 1.1 - 60.3) (Table 3). Factors associated with a prolonged time to cecum greater than one standard deviation above the mean (18 minutes) included older age, female sex, having the procedure performed at the hospital based unit, poor quality bowel preparation, having multiple past abdominal surgeries (in particular, having a past hysterectomy), and receiving higher medication doses for conscious sedation (Table 5).

Prolonged cecal intubation times were associated with nurse inexperience. Eighteen percent of procedures with a cecal intubation time greater than one standard deviation above the mean (167 of 923) were staffed by a nurse with 0-6 months of experience compared to $12 \%$ of procedures $(282$ of 2,320$)$ staffed by a nurse with greater than 6 months of experience $(\mathrm{p}<$ 0.001 by chi-square; $\mathrm{OR}_{\text {crude }}=1.60,95 \%$ CI $1.30,1.97$ ). This association also held after the multivariable analysis (Table 6) adjusting for potential confounding factors including patient age, sex, bowel preparation quality, BMI, ASA score, presence of multiple comorbidities, multiple past abdominal surgeries, past hysterectomy, severe diverticulosis, and polypectomy $\left(\mathrm{OR}_{\text {adjusted }}=1.34,95 \% \mathrm{CI} 1.01,1.78\right)$. The addition of physician procedure volume to the model also did not change this result.

\section{Total procedure time}

The mean total procedure time was 23.1 minutes (range 1.8 - 120.1) (Table 3). Factors associated with prolonged total procedure time included older age, having the procedure performed at the hospital-based unit, poor bowel preparation, the presence of multiple comorbidities, having multiple past abdominal surgeries, receiving higher medication doses for conscious sedation, and finding and removing one or more polyps (Table 5).

Prolonged procedure times were associated with nurse inexperience. Eighteen percent of procedures with a total procedure time greater than one standard deviation above the mean (182 of 1,031) were staffed by a nurse with 0-6 months of experience compared to $12 \%$ of procedures $(296$ of 2,524) staffed by a nurse with greater than 6 months of experience ( $\mathrm{p}<$ 0.001 by chi-square; $\mathrm{OR}_{\text {crude }}=1.61,95 \% \mathrm{CI} 1.32,1.97$ ). This association also held after the multivariable analysis (Table 6 ) adjusting for potential confounding factors including patient age, sex, bowel preparation quality, BMI, ASA score, presence of multiple comorbidities, multiple past abdominal surgeries, past hysterectomy, severe diverticulosis, and polypectomy $\left(\mathrm{OR}_{\text {adjusted }}=1.54,95 \% \mathrm{CI} 1.18,2.01\right)$. The addition of physician procedure volume to the model also did not change this result.

\section{Cecal intubation rate}

The overall cecal intubation rate was $95 \%$, with the terminal ileum examined in $28 \%$ of cases (Table 3). For analysis, however, the cecal intubation rate given that the bowel preparation was adequate and an attempt was made to reach the cecum was $93 \%$. This value is lower because 74 cases in which the cecum was reached were excluded because the bowel preparation was 
deemed poor or inadequate and the colonic mucosa was insufficiently examined. Factors that were associated with a reduced rate of cecal intubation are presented in Table 5.

As with the other outcomes, a reduced cecal intubation rate was associated with nurse inexperience. Nine percent of procedures during which the cecum was not reached (91 of 979) were staffed by a nurse with 0-6 months of experience compared to $5 \%$ of procedures (128 of $2,385)$ staffed by a nurse with greater than 6 months of experience ( $\mathrm{p}<0.001$ by chi-square; $\mathrm{OR}_{\text {crude }}=1.81,95 \% \mathrm{CI} 1.37,2.39$ ). This association also held after the multivariable analysis (Table 6) adjusting for potential confounding factors including patient age, sex, bowel preparation quality, BMI, ASA score, presence of multiple comorbidities, multiple past abdominal surgeries, past hysterectomy, severe diverticulosis, and polypectomy $\left(\mathrm{OR}_{\text {adjusted }}=\right.$ $1.90,95 \%$ CI $1.15,3.15)$. The addition of physician procedure volume to the model also did not change this result.

\section{DISCUSSION}

This study examined the effect of the level of GI endoscopy nursing experience on selected outcomes of screening colonoscopies performed by experienced attending physicians. We found that even after adjusting for factors known to be associated with difficult colonoscopies or colonoscopic complications, patients undergoing screening colonoscopy staffed by a nurse with 2 weeks or less of GI endoscopy nursing experience had approximately 10 times the odds of having an immediate procedural complication compared with procedures staffed by a nurse with greater than 2 weeks of GI endoscopy nursing experience. Additionally, screening colonoscopies staffed by nurses with 6 months or less of GI endoscopy nursing experience had approximately: 1.6 times the odds of a cecal intubation time greater than 1 standard deviation above the mean; 1.6 times the odds of a total procedure time greater than 1 standard deviation above the mean; and 1.8 times the odds of not reaching the cecum.

In contrast to the growing literature examining the learning curve for nurse endoscopists performing flexible sigmoidoscopy and colonoscopy, ${ }^{24,} 25$ to our knowledge the effect of GI endoscopy nurse experience on colonoscopy outcomes has not been previously reported. Moreover, it is not known whether similar effects would be observed for other GI procedures such as upper endoscopy, endoscopic ultrasound (EUS), or endoscopic retrograde cholangiopancreatography (ERCP). It is therefore somewhat difficult to contextualize our results, and our findings will need to be confirmed in other settings. Limited data within the field of gastroenterology is only peripherally helpful. In 1989, Matthews and colleagues performed an ex-vivo experiment utilizing a training protocol for ERCP nurses injecting contrast dye. ${ }^{26}$ They confirmed their hypothesis that inexperienced nurses injected contrast at higher pressures than did nurses experienced in ERCP techniques, and that after training sessions for the novice nurses, the injection pressures between the two groups were equivalent. This was not a clinical study, however, and there do not appear to be any published accounts of whether this improvement seen after training resulted in a decreased frequency of postERCP pancreatitis. In one other unrelated study, investigators found that nurses could better assess pain during colonoscopies than could the endoscopists, but quality of pain assessment was not correlated with nursing experience. ${ }^{27}$ Expanding the literature search to other procedural fields such as cardiac catheterization, interventional radiology, and bronchoscopy yields no other pertinent studies.

When interpreting the findings of our study, there are a number of limitations that must be considered. Because this was a retrospective analysis, there may be concerns about validity and bias. First, misclassification of the exposure of nursing experience is possible, but unlikely. For new nurses, the exact start dates were known and none of the nurses had prior experience in a GI procedures unit. For established nurses, start dates were also known, and even if there 
was some error in recording these, most nurses had far greater than 6 months of experience already, so the reported results would not be affected. It is also a strength of this study that both the experience level of every individual nurse was known for each colonoscopy in which they participated, and that the exact number of colonoscopies staffed by each nurse at every stage of the study was known. Moreover, every colonoscopy performed by an attending physician alone over the study time frame was included, thus limiting the bias that could result from selecting only the cases with known complications. Although there were a relatively small number of complications, we analyzed a large number of cases not only to identify them but to provide a high level of detail concerning other covariates in addition to nurse experience levels. We are also reassured that our regression model was stable because the crude odds ratio was essentially unchanged from the fully adjusted odds ratio.

Second, because only immediate complications were routinely recorded in our electronic endoscopy databases, it is almost certain that late complications were missed. While it is possible that the occurrence of a late complication may be related to nurse experience during the procedure, whether or not the complication itself was missed would not vary by nursing experience level and therefore should not affect the results. Because complications are reported by the endoscopist, this reporting should not vary by level of nurse experience either.

Additionally, attempting to capture late complications in an open healthcare system with a large rural catchment area is difficult, and the data would likely be unreliable. We would also note that the complications we detected did not include those most dreaded by endoscopists, for example perforation or death, but were instead reversible events. However, each of the complications was potentially life-threatening, and in procedure units without expertise in handling such events, these might have resulted in death or long-term sequelae.

Third, because we used data sources for which information is entered by physicians and nurses during the course of clinical care, data was missing for some variables. However, we saw no differential pattern to missing data between experienced and inexperienced nurses, and all covariates had less than $10 \%$ missing data with the exception of data on past abdominal surgeries (approximately 25\% missing). Moreover, that our study found the same predictors of difficult colonoscopies as previous investigations lends support to the validity of the data source. A related point is that while cases with two nurses present were almost exclusively training cases, we could not determine from our database if some fraction of these cases represented a handoff of care between two nurses.

An additional limitation is that because this is a single center study, the results may not be generalizable. Specifically, nurse training protocols may be different at other institutions; there may be differences between academic and private practice settings; nurse turnover rates in other settings may vary substantially from ours; and patient populations can vary in illness severity and other characteristics between centers. This is highlighted by the fact that there is no association between nurses and endoscopists at our center, hence the rationale for not including a proxy for physician experience as a potential confounding factor in our initial regression models. However, even after including a parameter for physician colonoscopy volume during the study time period, the results were unchanged. Another potential difference at our center is the mean time to cecum of 11 minutes, even after restricting the procedures to those performed by attending physicians. This is prolonged compared with some reports in the literature from expert technical colonoscopists, ${ }^{28}$ but in line with studies of routine clinical practice which report times from 7-11 minutes. ${ }^{7}, 11,18,21,29,30$ The immediate complication rate of $0.4 \%$ that we detected, however, is consistent with other estimates in the literature, ${ }^{4}$, 5,7 with the caveat that retrospective series often underestimate the total number of procedural complications. ${ }^{6}$ Our overall cecal intubation rate, too, was similar to those rates previously reported in the literature (most of which range between 91 and 99\%, depending on the study 
setting and colonoscopy indication), $5,7,12,13,15-19,30$ and met the goal set forth by the U.S. Multi-Society Task Force on Colorectal Cancer. ${ }^{31}$

The findings in this study make intuitive sense. Just as there is a learning curve for GI trainees learning colonoscopies, ${ }^{8-10}$ a learning curve for GI endoscopy nurses likely exists as well. The SGNA guidelines tacitly imply this, but rely on individualized training given that nurses can enter the field of gastroenterology with a wide range of previous experience. ${ }^{22}$ Nurses must not only master monitoring and recording vital signs, administering conscious sedation, and assessing sedation level, but must become intimately familiar with the colonoscopy procedure protocol, indications, findings, equipment, and therapeutic interventions. We would hypothesize, though cannot confirm from the data currently available to us, that nurse inexperience could predispose to complications, longer procedure times, and lower cecal intubation rates because each of the facets of the colonoscopy procedure is not familiar. For example, sedation may become too deep requiring reversal medications; an inexperienced nurse may not yet know the most effective way to apply abdominal pressure, or may not be able to anticipate when it is needed; and if polypectomy and cautery equipment are not familiar, several minutes may be spent readying these prior to using them. Interestingly, our data suggest that the solution may not be as simple as adding a second, supervising, nurse to the procedure room. Having a second nurse present was associated with increased complications, increased procedure times, and decreased cecal intubation rates, but these results were unchanged when the analysis was limited to cases with only one nurse present. During training cases with two nurses, both may devote more attention to teaching and explaining components of the procedure, and potentially less attention to the patient and colonoscopist. It is possible that complications could be prevented with educational interventions targeting physicians and nurses, such as longer nurse training intervals, physician-driven sedation protocols for new nurses, or ongoing tutorials by anesthesiologists, which highlight the at-risk period of a nurse's first two weeks in a procedures unit, or perhaps by increasing staffing for those procedures. We would stress, however, that all of these potential explanations are hypotheses and that further investigation is needed to determine which factors are most important and what types of interventions would be effective. Moreover, additional prospective research would be needed to determine whether nurse experience correlates with serious complications such as post-polypectomy bleeding, need for hospitalization, bowel perforation, or death.

In conclusion, nurse inexperience is associated with increased odds of screening colonoscopy immediate complications, prolonged procedure times, and decreased cecal intubation rates. These findings have potential implications for GI endoscopy nurse training, colonoscopy quality measures, patient safety, and procedure efficiency. Finally, targeting the procedures staffed by nurses new to the GI procedure unit may be a way to decrease a substantial proportion of immediate screening colonoscopy complications, but future research in this area is needed to evaluate this hypothesis.

\section{Acknowledgments}

Grant support: This work is funded in part by grants from the National Institutes of Health training grant T32 DK007634 and P30 DK3497.

\section{REFERENCES}

1. Screening for colorectal cancer: recommendation and rationale. Ann Intern Med 2002;137:129-31. [PubMed: 12118971]

2. Winawer S, Fletcher R, Rex D, Bond J, Burt R, Ferrucci J, et al. Colorectal cancer screening and surveillance: clinical guidelines and rationale-Update based on new evidence. Gastroenterology 2003;124:544-60. [PubMed: 12557158] 
3. Davila RE, Rajan E, Baron TH, Adler DG, Egan JV, Faigel DO, et al. ASGE guideline: colorectal cancer screening and surveillance. Gastrointest Endosc 2006;63:546-57. [PubMed: 16564851]

4. Dominitz JA, Eisen GM, Baron TH, Goldstein JL, Hirota WK, Jacobson BC, et al. Complications of colonoscopy. Gastrointest Endosc 2003;57:441-5. [PubMed: 12665750]

5. Wexner SD, Garbus JE, Singh JJ. A prospective analysis of 13,580 colonoscopies. Reevaluation of credentialing guidelines. Surg Endosc 2001;15:251-61. [PubMed: 11344424]

6. Bini EJ, Firoozi B, Choung RJ, Ali EM, Osman M, Weinshel EH. Systematic evaluation of complications related to endoscopy in a training setting: A prospective 30-day outcomes study. Gastrointest Endosc 2003;57:8-16. [PubMed: 12518123]

7. Nelson DB, McQuaid KR, Bond JH, Lieberman DA, Weiss DG, Johnston TK. Procedural success and complications of large-scale screening colonoscopy. Gastrointest Endosc 2002;55:307-14. [PubMed: 11868001]

8. Chak A, Cooper GS, Blades EW, Canto M, Sivak MV Jr. Prospective assessment of colonoscopic intubation skills in trainees. Gastrointest Endosc 1996;44:54-7. [PubMed: 8836717]

9. Marshall JB. Technical proficiency of trainees performing colonoscopy: a learning curve. Gastrointest Endosc 1995;42:287-91. [PubMed: 8536893]

10. McCashland T, Brand R, Lyden E, de Garmo P. The time and financial impact of training fellows in endoscopy. CORI Research Project. Clinical Outcomes Research Initiative. Am J Gastroenterol 2000;95:3129-32. [PubMed: 11095329]

11. Bernstein C, Thorn M, Monsees K, Spell R, O’Connor JB. A prospective study of factors that determine cecal intubation time at colonoscopy. Gastrointest Endosc 2005;61:72-5. [PubMed: 15672059]

12. Harewood GC. Relationship of colonoscopy completion rates and endoscopist features. Dig Dis Sci 2005;50:47-51. [PubMed: 15712636]

13. Cirocco WC, Rusin LC. Factors that predict incomplete colonoscopy. Dis Colon Rectum 1995;38:964-8. [PubMed: 7656745]

14. Dafnis G, Granath F, Pahlman L, Ekbom A, Blomqvist P. Patient factors influencing the completion rate in colonoscopy. Dig Liver Dis 2005;37:113-8. [PubMed: 15733524]

15. Anderson JC, Gonzalez JD, Messina CR, Pollack BJ. Factors that predict incomplete colonoscopy: thinner is not always better. Am J Gastroenterol 2000;95:2784-7. [PubMed: 11051348]

16. Anderson JC, Messina CR, Cohn W, Gottfried E, Ingber S, Bernstein G, et al. Factors predictive of difficult colonoscopy. Gastrointest Endosc 2001;54:558-62. [PubMed: 11677470]

17. Aslinia F, Uradomo L, Steele A, Greenwald BD, Raufman JP. Quality assessment of colonoscopic cecal intubation: an analysis of 6 years of continuous practice at a university hospital. Am J Gastroenterol 2006;101:721-31. [PubMed: 16494586]

18. Kim WH, Cho YJ, Park JY, Min PK, Kang JK, Park IS. Factors affecting insertion time and patient discomfort during colonoscopy. Gastrointest Endosc 2000;52:600-5. [PubMed: 11060182]

19. Takahashi Y, Tanaka H, Kinjo M, Sakumoto K. Prospective evaluation of factors predicting difficulty and pain during sedation-free colonoscopy. Dis Colon Rectum 2005;48:1295-300. [PubMed: 15793639]

20. Walter LC, de Garmo P, Covinsky KE. Association of older age and female sex with inadequate reach of screening flexible sigmoidoscopy. Am J Med 2004;116:174-8. [PubMed: 14749161]

21. Zuber-Jerger I, Kullmann F. A prospective study of factors that determine cecal intubation time at colonoscopy. Gastrointest Endosc 2006;63:358-9. [PubMed: 16427963]

22. SGNA. Standards of clinical nursing practice and role delineation statements. 2005 [accessed April 4, 2007]. http://www.sgna.org/Resources/guidelines/guideline8.cfm

23. Keats AS. The ASA classification of physical status--a recapitulation. Anesthesiology 1978;49:2336. [PubMed: 697075]

24. Verschuur EM, Kuipers EJ, Siersema PD. Nurses working in GI and endoscopic practice: a review. Gastrointest Endosc 2007;65:469-79. [PubMed: 17321249]

25. Ganz RA, Utley DS, Stern RA, Jackson J, Batts KP, Termin P. Complete ablation of esophageal epithelium with a balloon-based bipolar electrode: a phased evaluation in the porcine and in the human esophagus. Gastrointest Endosc 2004;60:1002-10. [PubMed: 15605025] 
26. Mathews JS, Maher KA, Cattau EL Jr. The role of endoscopic retrograde cholangiopancreatography injection training sessions for the gastroenterology nurse and associate. Gastroenterol Nurs 1989;12:106-8. [PubMed: 2487820]

27. Ramakrishnan S, Yiannakou JY, Ellis WR, Bain IM. Assessment of patient pain at colonoscopy: are nurses better than endoscopists? J R Soc Med 2004;97:432-3. [PubMed: 15340023]

28. Deenadayalu VP, Chadalawada V, Rex DK. 170 degrees wide-angle colonoscope: effect on efficiency and miss rates. Am J Gastroenterol 2004;99:2138-42. [PubMed: 15554993]

29. Shumaker DA, Zaman A, Katon RM. A randomized controlled trial in a training institution comparing a pediatric variable stiffness colonoscope, a pediatric colonoscope, and an adult colonoscope. Gastrointest Endosc 2002;55:172-9. [PubMed: 11818918]

30. Barclay RL, Vicari JJ, Doughty AS, Johanson JF, Greenlaw RL. Colonoscopic withdrawal times and adenoma detection during screening colonoscopy. N Engl J Med 2006;355:2533-41. [PubMed: 17167136]

31. Rex DK, Bond JH, Winawer S, Levin TR, Burt RW, Johnson DA, et al. Quality in the technical performance of colonoscopy and the continuous quality improvement process for colonoscopy: recommendations of the U.S. Multi-Society Task Force on Colorectal Cancer. Am J Gastroenterol 2002;97:1296-308. [PubMed: 12094842] 


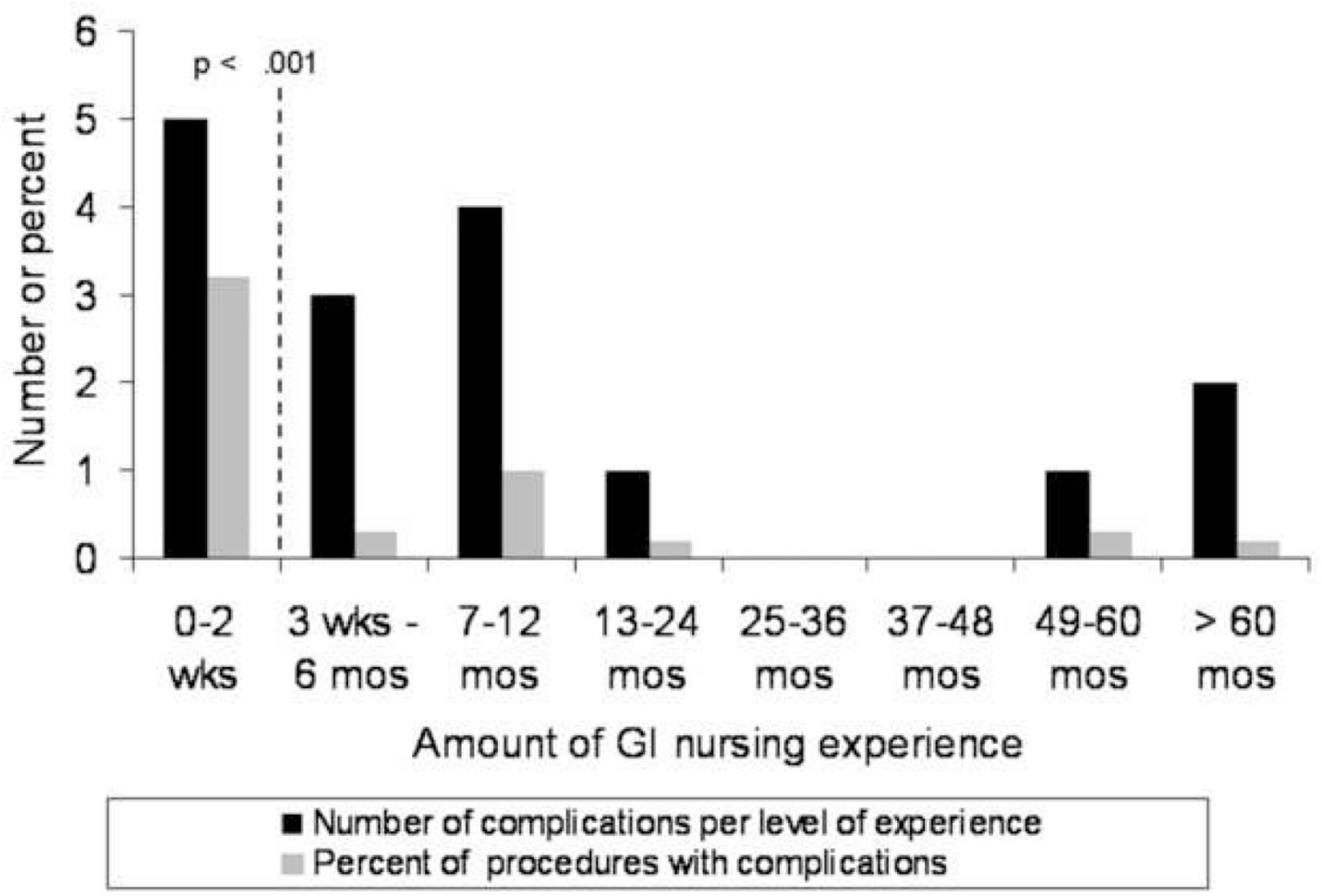

Figure 1.

Association between amount of GI endoscopy nursing experience and immediate complications from screening colonoscopy. Note that both absolute numbers and proportions are presented on this figure, as specified on the y-axis. The black bars represent the total number of complications occurring at each level of nursing experience. The grey bars represent the proportion of cases in which complications occurred for each level of nursing experience. The dotted line shows that for the primary outcome of complications, nurse experience was dichotomized at two weeks of experience or less. By chi-square, $p<0.001$ for the overall association comparing greater and less than two weeks of experience. 
Table 1

Patient characteristics* $(\mathrm{n}=3614 \text { patients } ; \mathrm{n}=3631 \text { screening colonoscopies })^{\dagger}$

\begin{tabular}{|c|c|}
\hline Characteristic & Mean or percent \\
\hline Mean age (range, $\pm \mathrm{SD}$ ) & $58.4(21-90) \pm 9.5$ \\
\hline$\%$ male & 42.2 \\
\hline $\mathrm{BMI}$ (mean, range, $\pm \mathrm{SD}$ ) & $27.7(14-76) \pm 6.1$ \\
\hline underweight $(\%$ BMI < 18.5) & 1.2 \\
\hline normal (\% BMI 18.5 - 24.9) & 35.2 \\
\hline overweight (\% BMI 25 - 29.9) & 36.0 \\
\hline obese (\% BMI 30 - 39.9) & 23.2 \\
\hline morbidly obese ( $\%$ BMI > 40) & 4.4 \\
\hline \multicolumn{2}{|l|}{ Other medical conditions $(\%)$} \\
\hline any comorbidity & 86.2 \\
\hline multiple comorbidities & 46.5 \\
\hline HTN/CAD & 51.6 \\
\hline DM & 15.0 \\
\hline OSA/snoring & 55.2 \\
\hline COPD/other respiratory condition & 14.5 \\
\hline \multicolumn{2}{|l|}{ Past surgeries $(\%)$} \\
\hline any past abdominal surgery & 56.0 \\
\hline past multiple abdominal surgeries & 15.8 \\
\hline $\mathrm{s} / \mathrm{p}$ hysterectomy & 24.3 \\
\hline $\mathrm{s} / \mathrm{p}$ bowel resection & 2.2 \\
\hline $\mathrm{s} / \mathrm{p}$ hernia surgery & 13.0 \\
\hline $\mathrm{s} / \mathrm{p}$ cholecystectomy & 13.2 \\
\hline s/p appendectomy & 21.6 \\
\hline $\mathrm{s} / \mathrm{p}$ other abdominal surgery & 0.5 \\
\hline \multicolumn{2}{|l|}{ Pre-procedure ASA score $(\%)$} \\
\hline I — normal healthy patient & 45.5 \\
\hline II - mild or moderate systemic disease & 51.7 \\
\hline III — severe systemic disease & 2.8 \\
\hline
\end{tabular}

\footnotetext{
*Abbreviations: $\mathrm{BMI}=$ body mass index; $\mathrm{HTN}=$ hypertension; $\mathrm{CAD}=$ coronary artery disease; $\mathrm{DM}=$ diabetes; $\mathrm{OSA}=$ obstructive sleep apnea; $\mathrm{COPD}$ $=$ chronic obstructive pulmonary disease; ASA = American Society of Anesthesiologists

${ }^{\dagger} 17$ colonoscopies were repeated due to poor or inadequate bowel preparation
} 
Nurse characteristics

\section{Table 2}

\begin{tabular}{lc}
\hline Total number of nurses during study period & 29 \\
Nurses at the beginning (\#) & 10 \\
Nurses at the end (\#) & 15 \\
New nurses during the study period & 19 \\
$\quad$ Nurse turnover (\# leaving during study period) & $157(1-583) \pm 165$ \\
Nursing experience of the primary nurse & $281(1-799) \pm 204$ \\
Mean weeks experience (range, \pm SD) & $347(9.6)$ \\
Mean number of procedures for new nurses (range, \pm SD) & $213(8-563) \pm 161$ \\
Number of procedures with two nurses present (\#, \%) & $433(108-728) \pm 148$ \\
For the second nurse present: & \\
Mean weeks experience (range, \pm SD) & \\
Mean number of procedures for new nurses (range, \pm SD) & \\
\hline
\end{tabular}

* Primary nurse defined as the nurse primarily responsible for monitoring, administering sedation, and assisting with technical aspects of the procedure. 


\section{Screening colonoscopy characteristics}

\section{Table 3}

Total number of screening colonoscopies during

study period (attending only performing)

Total number of all colonoscopies during study
period (all indications; fellows and attendings)

Indication for colonoscopy (\%)

Routine screening

High risk screening

Location of procedure (\%)

Hospital-based unit

Off-site unit

Number of physicians performing procedures

Mean number of procedures per MD (range)

Sedation medications

Mean fentanyl dose (range, $\pm \mathrm{SD}$; micrograms)

Mean midazolam dose (range, $\pm \mathrm{SD}$; milligrams)

Patients receiving adjunct promethazine (\%)

Bowel preparation quality (physician-assessed) (\%)

Excellent

Good

Fair

Poor

Unsatisfactory

Not reported

Physician-rated procedure difficulty $(\%)$

Not difficult or accomplished with ease $\quad 79.4$

Difficult 10.5

Not reported 10.1

Overall colonoscopy completion rates $(\%)$

Reaching cecum or ileum 95.3

Examining ileum ${ }^{\dagger} \quad 28.3$

Incomplete 4.7

Completion rate for cases with adequate bowel preparation 93.5

in which an attempt for completion was made $(\%)$

Findings and maneuvers on colonoscopy $(\%)$

Any diverticulosis

Severe diverticulosis 7.3

Any polyp 44.3

Polypectomy performed 44.1

Multiple polyps or polypectomies 23.3

Physician-reported patient tolerance $(\%)$

Tolerated well

Tolerated fairly well

Tolerated

Tolerated poorly 
Not reported

Procedure times

Time to cecum (mean minutes; range; SD)

Total time (mean minutes; range; SD)

Immediate complications

No immediate complications (\%)

Any immediate complication (\#, \%)

Bradycardia (\#)

Hypotension (\#)

Respiratory depression (\#)

Colonic perforation (\#)

Death (\#)

Patients receiving reversal agents (\#, \%)
11.3

$11(1.1-60.3) \pm 7.4$

$23.1(1.8-120.1) \pm 11.2$

99.6
$16(0.4)$
7
2
7
0
0
$11(0.3)$

* The cecum was reached in 74 cases with poor or unsatisfactory preparation, but it was deemed that these examinations did not adequately evaluate the colonic mucosa.

${ }^{\dagger}$ Ileal intubation performed at the discretion of the endoscopist for screening colonoscopies. 


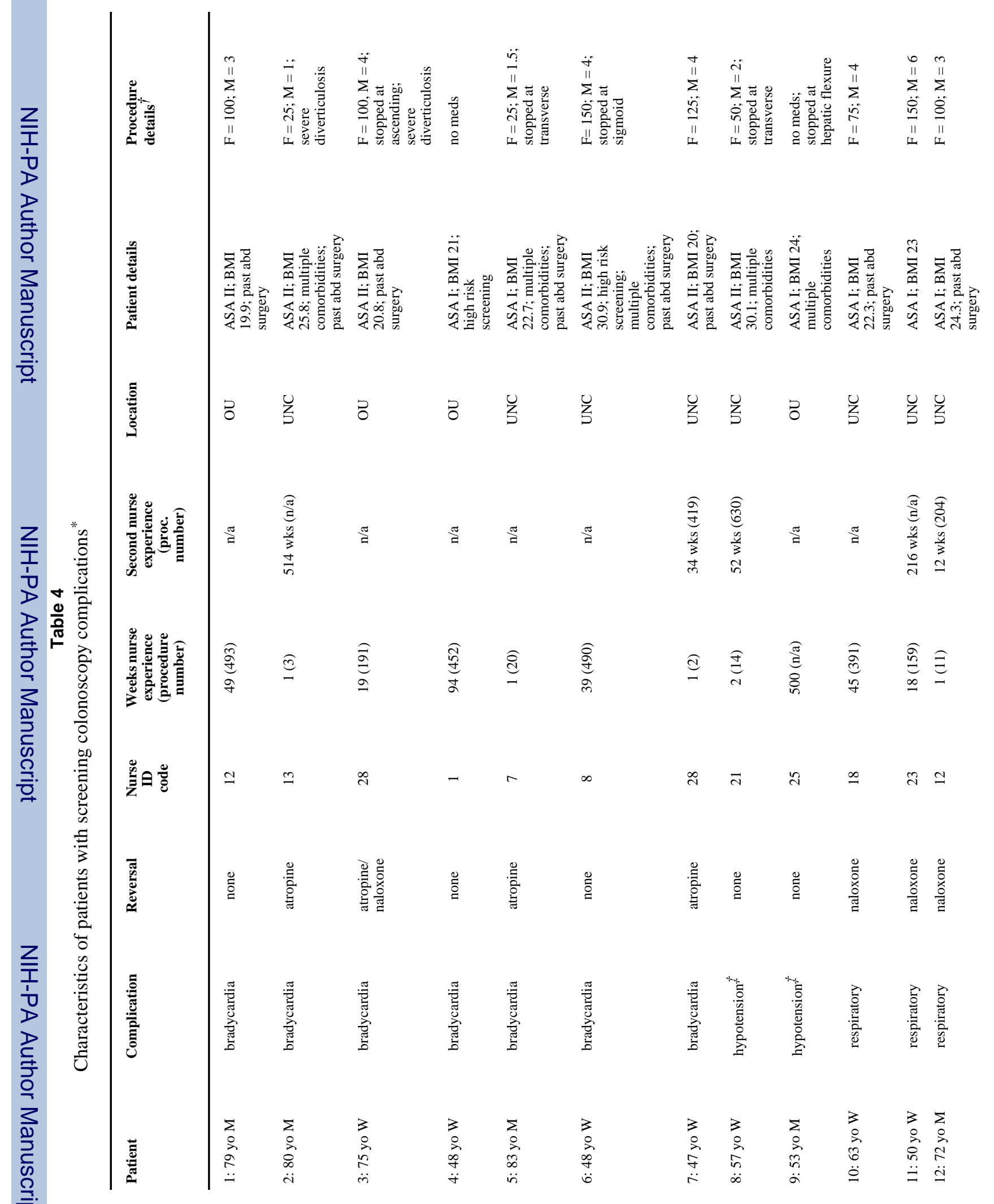


Dellon et al.

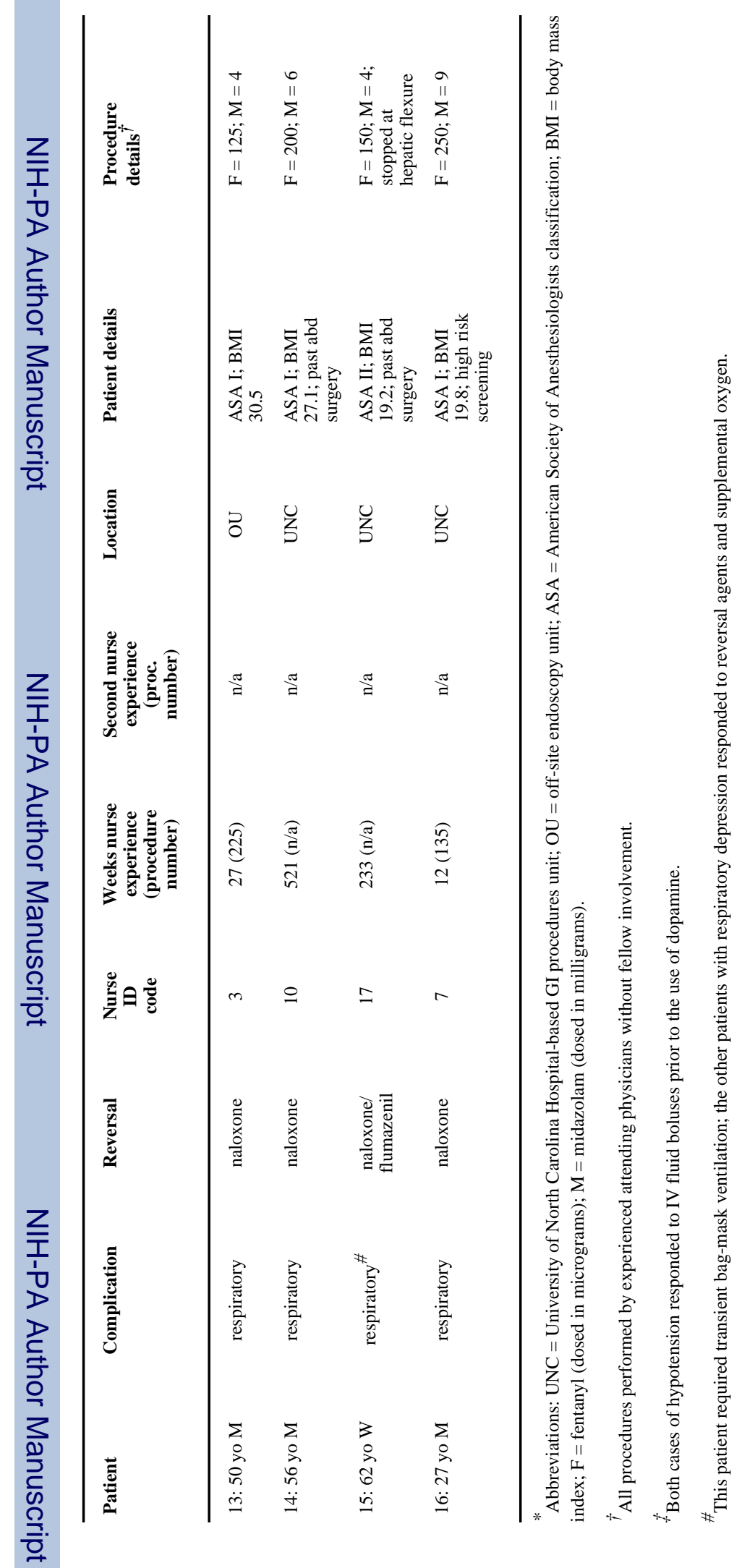




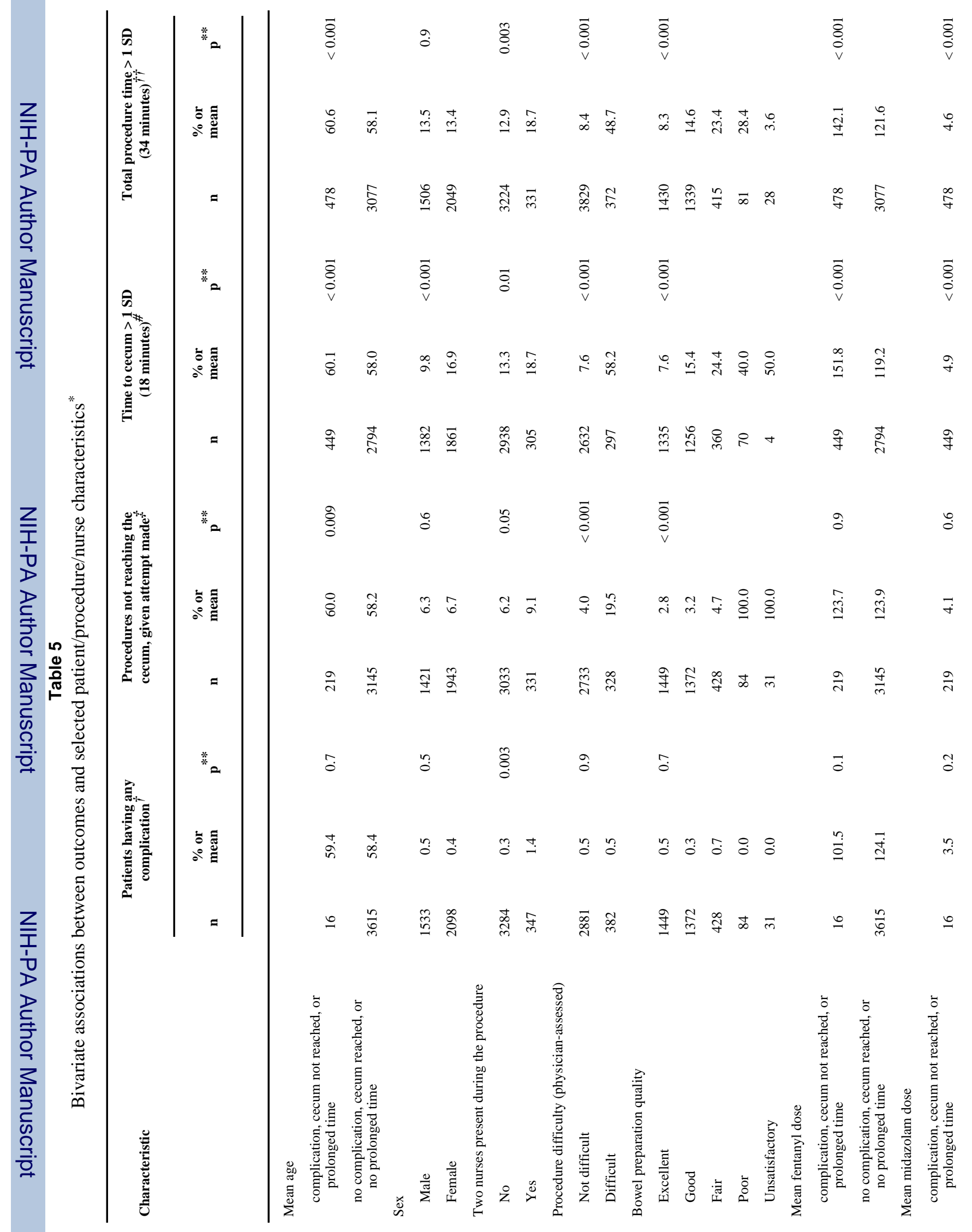

Gastrointest Endosc. Author manuscript; available in PMC 2010 August 1. 
Dellon et al.

Page 20

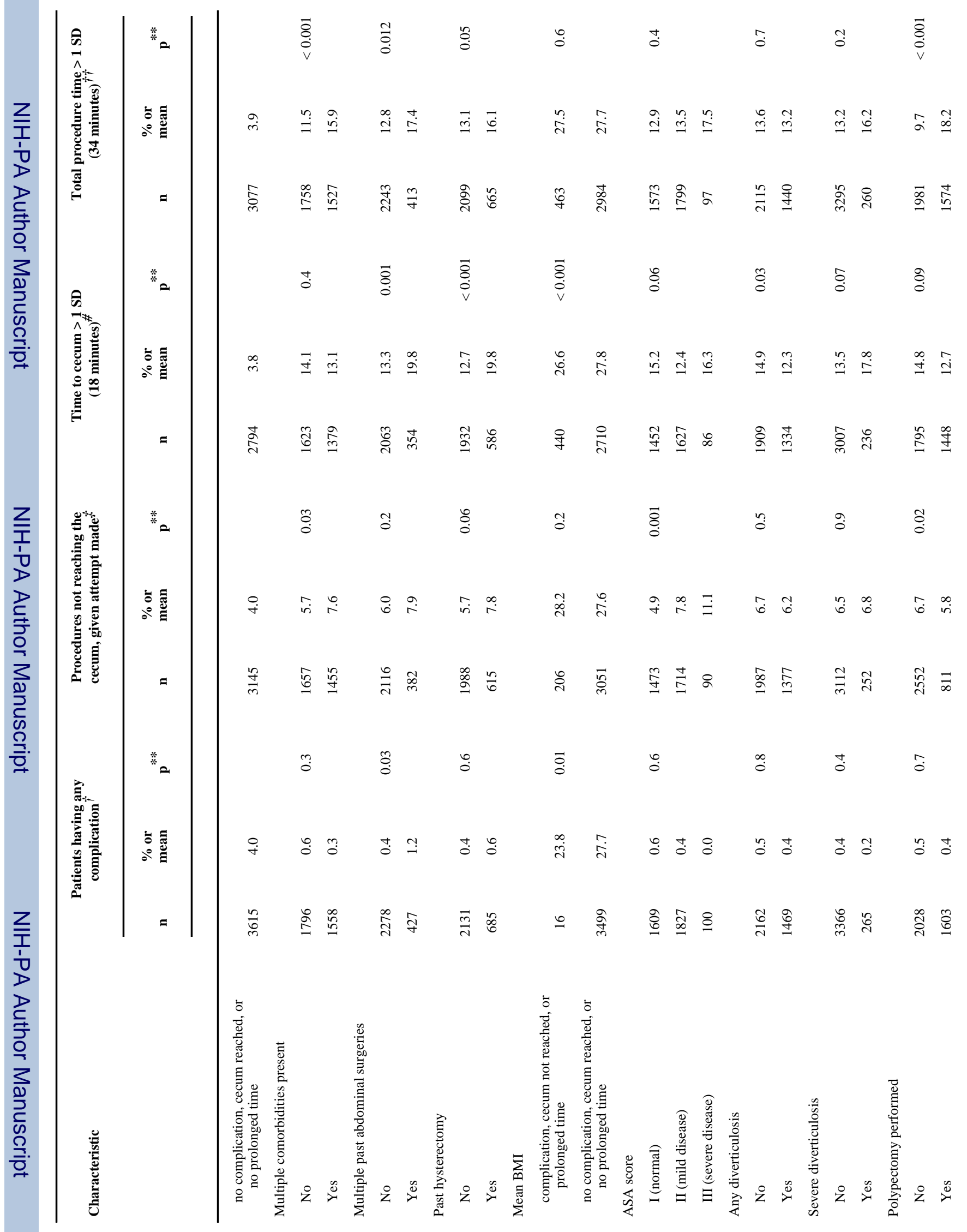

Gastrointest Endosc. Author manuscript; available in PMC 2010 August 1. 
Dellon et al.

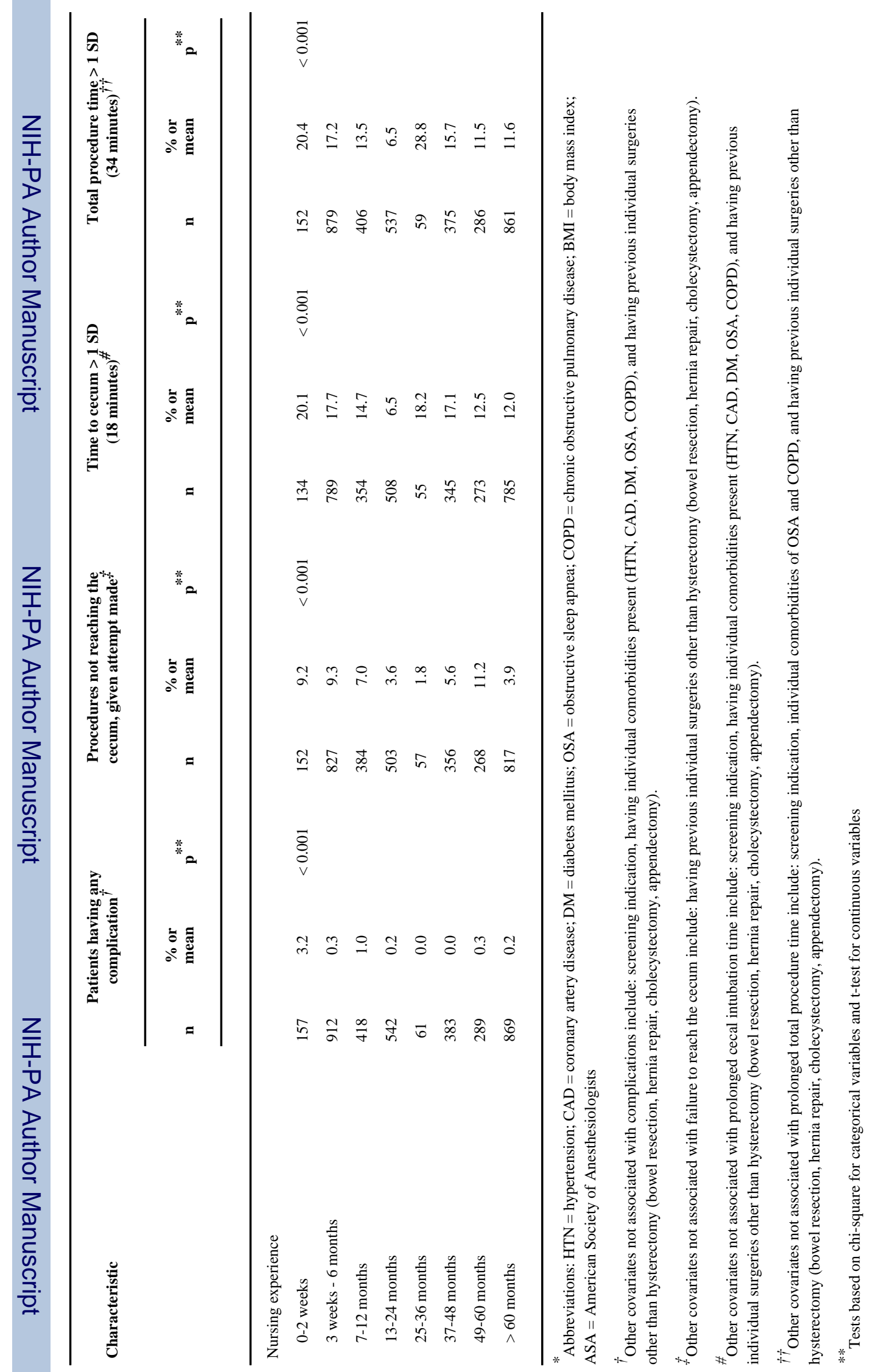

Gastrointest Endosc. Author manuscript; available in PMC 2010 August 1. 
Table 6

Multivariate analysis of nursing experience and screening colonoscopy outcomes*

\begin{tabular}{|c|c|c|c|c|}
\hline & $\mathbf{O R}_{\text {crude }}$ & $95 \% \mathrm{CI}$ & $\mathbf{O R}_{\text {adjusted }}^{\dagger}$ & $95 \% \mathrm{C} \mathrm{I}$ \\
\hline \multicolumn{5}{|l|}{ Immediate procedural complication } \\
\hline $0-2$ weeks experience $/>2$ weeks experience & 10.4 & $3.55,30.2$ & 10.5 & $2.26,49.1$ \\
\hline \multicolumn{5}{|l|}{ Time to cecum $>1 \mathrm{SD}$ (18 minutes $)$} \\
\hline $0-6$ months experience / > 6 months experience & 1.60 & $1.30,1.97$ & 1.34 & $1.01,1.78$ \\
\hline \multicolumn{5}{|l|}{ Total procedure time $>1 \mathrm{SD}$ (34 minutes) } \\
\hline 0-6 months experience / > 6 months experience & 1.61 & $1.32,1.97$ & 1.54 & $1.18,2.01$ \\
\hline \multicolumn{5}{|l|}{ Cecal intubation rate, given that an attempt was made ${ }^{* *}$} \\
\hline 0-6 months experience / > 6 months experience & 1.81 & $1.37,2.39$ & 1.90 & $1.15,3.15$ \\
\hline \multicolumn{5}{|c|}{ * Multivariate analysis performed using logistic regression with an analysis of covariance strategy } \\
\hline
\end{tabular}

